\title{
PENERAPAN ALGORITMA BOYER MOORE PADA AUTOMATIC LINK PADA CONTENT WEBSITE
}

\author{
Didik, Guidio L, Ginting \\ Program Studi Teknik Informatika STMIK Budi Darma, Medan, Indonesia \\ Email: Didikpriadi86@gmail.com
}

\begin{abstract}
Abstrak
Membangun website dibutuhkan suatu perencanaan yang baik agar website tersebut dapat digunakan secara efektif dan efesien. Adapun tahapan yang dilakukan dalam membangun website adalah dimulai dengan mengumpulkan data kemudian mempelajari data tersebut, selanjutnya dilakukan perencanaan yang kemudiandituangkan dalam bentuk rancangan, kemudian rancangan tersebut dikembangkan dan dilakukan Dalam membangun suatu website tentunya memiliki masalah tersendiri, seperti tampilan interface, pengolahan data, performance, interaksi dengan pengguna, dan lain-lain. Untuk membangun suatu website yang memiliki banyak menu, merupakan suatu masalah bagi pembangun, karena ruang untuk menempatkan menu akan sangat terbatas jika ditujukan pada perangkat yang memiliki tampilan yang kecil seperti handphone. Algoritma pada metode string matching yang digunakan dalam penelitian ini adalah algoritma Boyer Moore algoritma ini dianggap sebagai algoritma aplikasi umum yang paling efisien, algoritma Boyer Moore mencakup algoritma pencocokan string yang paling efisien.
\end{abstract}

Kata kunci : Pencarian String Matching, Boyer Moore

\begin{abstract}
Building a website requires a good plan so that the website can be used effectively and efficiently. The stages carried out in building a website are started by collecting data then studying the data, then planning is carried out which is then poured in the form of a design, then the design is developed and carried out. In building a website, it certainly has its own problems, such as interface display, data processing, performance, interaction with users, and others. To build a website that has a lot of menus, is a problem for builders, because the space to place a menu will be very limited if it is aimed at devices that have a small display such as a cellphone. The algorithm in the string matching method used in this study is the Boyer Moore algorithm, this algorithm is considered the most efficient general application algorithm, the Boyer Moore algorithm includes the most efficient string matching algorithm.
\end{abstract}

Keywords: String Matching Search, Boyer Moore

\section{PENDAHULUAN}

Website adalah sekumpulan halaman web yang saling berhubungan yang umumnya berada pada pladen yang sama berisikan kumpulan informasi yang disediakan secara perorangan, kelompok, atau organisasi. URL adalah Uniform Resource Locator, yaitu cara penamaan alamat file di internet. URL merupakan serangkaian karakter (dapat berupa huruf, angka, ataupun simbol) yang sesuai dengan format standar yang sudah ditentukan, URL digunakan untuk menunjukkan alamat/address suatu sumber yang ada [1].

Dalam membangun website dibutuhkan suatu perencanaan yang baik agar website tersebut dapat digunakan secara efektif dan efesien. Adapun tahapan yang dilakukan dalam membangun website adalah dimulai dengan mengumpulkan data kemudian mempelajari data tersebut, selanjutnya dilakukan perencanaan yang kemudian dituangkan dalam bentuk rancangan, kemudian rancangan tersebut dikembangkan dan dilakukan pengujian. Dari tahapan pembangunan website tersebut, maka akan menghasilkan suatu website yang baik[2].

Algoritma pada metode string matching yang digunakan dalam penelitian ini adalah algoritma Boyer Moore. Algoritma Boyer Moore adalah salah satu algoritma pencarian string, yang diterbitkan oleh Robert S. Boyer, dan J. Strother Moore pada tahun 1977. Algoritma ini dianggap sebagai algoritma aplikasi umum yang paling efisien. Tidak seperti algoritma pencarian string yang ditemukan sebelumnya, algoritma Boyer-Moore mulai mencocokkan karakter dari sisi kanan pola. Ide dibalik algoritma ini adalah bahwa dengan memulai karakter yang cocok dari kanan, dan bukan dari kiri,lebih banyak informasi akan didapat. Algoritma Boyer Moore mencakup algoritma pencocokan string yang paling efisien dibandingkan algoritma pencocokan string lainnya[4].

\section{TEORITIS}

\subsection{Algoritma}

Pengertian Alagoritma adalah urutan langkah - langkah logis penyelesaian masalah yang disusun secara sistematis dan logis. kata logis merupakan kata kunci dalam algoritma, Langkah - langkah dalam Algoritma harus logis dan harus dapat ditentukan bernilai salah atau benar[1]. 
Kata Algoritma ditemukan oleh seorang matematikawan dari persia yang bernama Abu Abullah Ibnu Musa AlKhwarizmi. Dari masa kemasa algoritma mulai berkembang diabad ke 18. Algoritma memiliki tiga bentuk dasar antara lain:

\subsection{String Matching}

String matching adalah proses pencarian semua kemunculan query yang selanjutnya disebut pattern ke dalam string yang lebih panjang (teks). Pattern dilambangkan dengan $\mathrm{x}=\mathrm{x}$ [0..m-1] dan panjangnya adalah $\mathrm{m}$. Teks dilambangkan dengan $\mathrm{y}=\mathrm{y}$ [0..n-1] dan panjangnya adalah $\mathrm{n}$. String matching dibagi menjadi dua, yaitu exact matching dan heuristic matching[2].

\section{ANALISA DAN PEMBAHASAN}

Dalam membangun suatu website tentunya memiliki tantangan tersediri, masalah yang dihadapi dalam membangun website salah satu adalah manajemen kontent agar kontent dalam website tersebut tidak menggangu informasi yang disampaikan pada website tersebut. Area informasi dalam satu halaman website akan sangat terbatas jika website tersebut ditujukan untuk perangkat smartphone karena layar smartphone cukup kecil jika dibandingkan dengan layar laptop. Oleh sebab itu penulis menyimpulkan bahwa untuk membangun suatu aplikasi website pada smartphone dibutuhkan suatu strategi unik agar kontent pada website tersebut tidak ada yang hilang.

Pada penelitian tersebut penulis akan membahas bagaimana membangun sebuah website yang menu dari website tersebut dapat menjadi bagian dari informasi yang disampaikan, dengan kata lain jika ada kata pada informasi yang disampaikan merupakan link untuk menuju halaman lain maka secara otomatis kata tersebut menjadi hyperlink atau Uniform Resuce Locator (URL) dari website tersebut, dengan demikian area yang dibutuhkan untuk meletakkan menu menjadi berkurang. Untuk melakukan pencocokan URL dengan struktur kalimat pada informasi yang disampaikan, maka penulis menerapkan algoritma boyer moore pada pencocokan string. Algoritma Boyer moore dalam melakukan pencocokan teks berdasarkan nilai dari Bad Character dan Good Suffix untuk mencejagah pencarian yang sia-sia sehingga proses pencarian menjadi lebih cepat

\subsection{Pembahasan}

Untuk memudahkan penulis dalam penerapan algoritma boyer moore pada automatic URL, maka penulis mencontohkan hal tersebut pada suatu aplikasi website, dimana website tersebut terdiri dari 5 file php, setiap file memuat informasi seputar dari nama filenya. Nama-nama dari file website tersebut dapat dilihat pada gambar 3.1 dibawah ini.
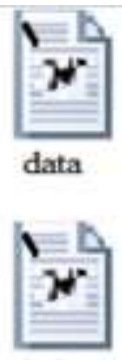

abakus

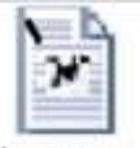

komputer

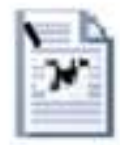

slide rule

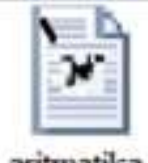

aritmatika

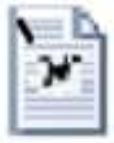

mesin
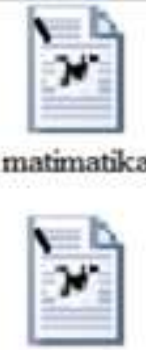

kalkulator
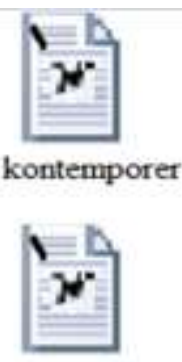

informasi

Gambar 1. File halaman website

Salah satu informasi yang disampaikan dari salah satu file php diatas dapat dilihat pada gambar dibawah ini

Komputer idalah alat yang dipakai untuk meng olah de ta menurut perintah yang telah diprogiam:

Kata komputer semula dipergunakan untuk menggambarkan orang yang perkerjaannye melakikan perhitungan aritmetika, dengan a tau tanpa alat bantu, tetapi arti lata ini kemudian' 'dipindahican kepeda mesin itu sendir. Asal mulanya, pengolahan informasi hampir eksklusif berhubungan dengan masalah arimatika, tetapi komputer modern dipakai untuk banyak tugas jang tidak berhubungan denģan matematika.

Dalam definisi seperti itu terdapat alat seperti slide nite, jenis kalkufator mekanik mulai, 'dari abakus dan seterusnya, sampai semua homputer elektronik yang kontemporer. Istilah lebih' baik yang cocok untuk arti luas seperti "kcomputer" adalah "Yang memproses informa si" atau' "sistem pengolah informasi."

Gambar 2. Muatan Informasi dari File PHP

Sebelum melakukan pencocokan string dari nama fie php dengan string dari informasi yang ditampilkan maka sebelumnya dilakukan proses proprocessing dari algoritma boyer moore. Sebagai contoh dari proses pencocokan 
string dari nama file php dengan string informasi yang ditampilkan maka penulis telah menentukan teks dan patter sebagai berikut :

Teks : : LINK MEMBANTU MENCARI INFORMASI

Pattern : INFORMASI

Setelah teks dan pattern telah ditentukan maka tahap selanjutnya adalah menentukan nilai $\mathrm{OH}$ dan $\mathrm{MH}$ dari pattern "INFORMASI"

Tabel 1. Nilai $\mathrm{OH}$ dan $\mathrm{MH}$ dengan pattern "INFORMASI"

\begin{tabular}{llllllllll}
\hline Index & 1 & 2 & 3 & 4 & 5 & 6 & 7 & 8 & 9 \\
\hline Pattern & I & N & F & O & R & M & A & S & I \\
\hline OH & 0 & 7 & 6 & 5 & 4 & 3 & 2 & 1 & 0 \\
\hline MH & 9 & 9 & 9 & 9 & 9 & 9 & 9 & 8 & 1 \\
\hline
\end{tabular}

\begin{tabular}{|l|l|l|l|l|l|l|l|l|l|l|l|l|l|l|l|l|l|l|l|l|l|l|l|l|l|l|l|l|l|}
\hline L & I & N & K & & M & E & M & B & A & T & U & & M & E & N & C & A & R & I & & I & N & F & O & R & M & A & S & I \\
\hline i & n & f & o & r & m & a & s & i & i & (1) \\
\hline
\end{tabular}

Berikut adalah langkah awal dalam perbandingan karakter "I" dengan karakter "B" pada teks. Terjadi ketidakcocokan sehingga pergeseran selanjutnya berdaasrkan nilai dari tabel $\mathrm{OH}$ dengan karakter " $\mathrm{B}$ " yaitu sebesar 9

\begin{tabular}{|c|c|c|c|c|c|c|c|c|c|c|c|c|c|c|c|c|c|c|c|c|}
\hline $\mathrm{A}$ & $\mathrm{T}$ & $\mathrm{U}$ & & $\mathrm{M}$ & $\mathrm{E}$ & $\mathrm{N}$ & $\mathrm{C}$ & $\mathrm{A}$ & $\mathrm{R}$ & $\mathrm{I}$ & & $\mathrm{I}$ & $\mathrm{N}$ & $\mathrm{F}$ & $\mathrm{O}$ & $\mathrm{R}$ & $\mathrm{M}$ & $\mathrm{A}$ & $\mathrm{S}$ & $\mathrm{I}$ \\
\hline $\mathrm{i}$ & $\mathrm{n}$ & $\mathrm{f}$ & $\mathrm{o}$ & $\mathrm{r}$ & $\mathrm{m}$ & $\mathrm{a}$ & $\mathrm{s}$ & $\mathrm{i}$ & \multicolumn{1}{|c|}{} & \\
\hline
\end{tabular}

Pada tahap kedua terjadi perbandingan karakter karakter "I" dengan karakter "A" pada teks. Terjadi ketidakcocokan sehingga pergeseran selanjutnya berdaasrkan nilai dari tabel $\mathrm{OH}$ dengan karakter "A" yaitu sebesar 2

\begin{tabular}{|c|c|c|c|c|c|c|c|c|}
\hline $\mathrm{I}$ & $\mathrm{N}$ & $\mathrm{F}$ & $\mathrm{O}$ & $\mathrm{R}$ & $\mathrm{M}$ & $\mathrm{A}$ & $\mathrm{S}$ & $\mathrm{I}$ \\
\hline $\mathrm{I}$ & $\mathrm{N}$ & $\mathrm{F}$ & $\mathrm{O}$ & $\mathrm{R}$ & $\mathrm{M}$ & $\mathrm{A}$ & $\mathrm{S}$ & $\mathrm{I}$ \\
\hline
\end{tabular}

Pada tahap terakhir, terjadi perbandingan karakter "I" pada pattern dengan karakter "I" pada teks. Terjadi kecocokan kata .

\section{IMPLEMENTASI}

Tampilan interface dari aplikasi automatic url dengan menerapkan algoritma boyer yang telah dibangun penulis dapat dilihat pada gambar 3. Pada tampilan tersebut terdapat isian judul berita dan isi berita, adapun tampilan dari input berita tersebut dapat dilihat pada gambar dibawah ini.

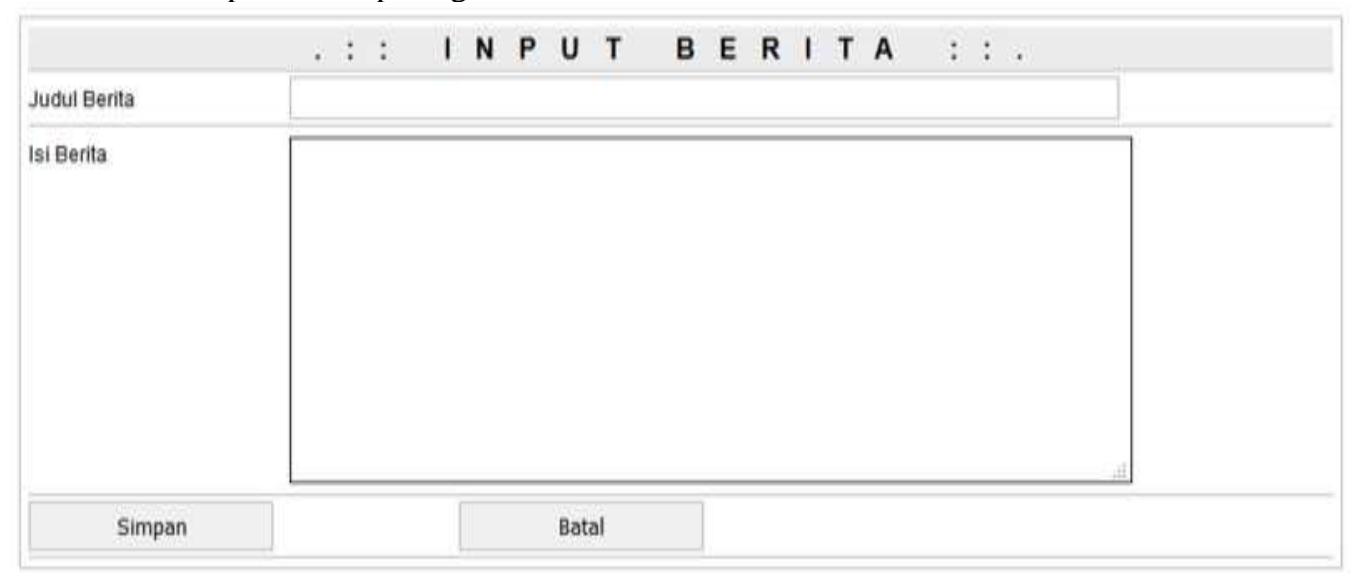

Gambar 3. Tampilan Input Berita

\section{KESIMPULAN}

Berdasarkan hasil yang didapat dalam penelitian dan penyusunan skripsi ini serta disesuaikan dengan tujuan, maka diperoleh kesimpulan sebagai berikut:

1. Mengetahui informasi lebih mudah dengan dibutuhkan aplikasi pencarian sehingga informasi yang didapat lebih akurat dan lebih cepat.

2. Dalam aplikasi proses pencarian maka di butuhkan algoritma boyer moore karna lebih efesiensi dari pada krja algorimanya.

3. Dibangunnya aplikasi pencarian ini dengan menggunakan bahasa pemogram xampp sangat memberikan kemudahan kepada peneliti dalam menerapkan setiap rancangan aplikasi yang telah didesain sebelumnya 


\section{REFERENCES}

[1] W. F. Kusuma, "Pengembangan Halaman Web Menggunakan Xml,” J. Tek. Inform., vol. 6, no. 2, 2015

[2] P. S. Hasugian, "Website Sebagai Media Promosi," Peranc. WEBSITE SEBAGAI MEDIA PROMOSI DAN Inf. Penda, vol. 3, no. 1, pp. 82-86, 2018.

[3] P. Perancangan, "Perancangan Desain Website Sebagai Salah Satu Media Promosi the Cobbler Yogyakarta," pp. 1-22, 2017.

[4] R. I. Darmawan and A. H. Setianingrum, “1574-3879-1-Pb,” vol. 5341, no. April, pp. 53-62, 2018.

[5] A. Prayitno, A. Johar, and Y. Setiawan, "Implementasi algoritma turbo boyer moore pada aplikasi kamus istilah biologi berbasis android," vol. 6, no. 1, pp. 13-23, 2018.

[6] G. G. Maulana, "Pembelajaran Dasar Algoritma Dan Pemrograman Menggunakan El-Goritma Berbasis Web," J. Tek. Mesin, vol. 6, no. 2, p. 8, 2017.

[7] P. Translator, B. Pascal, D. Effendi, T. Hartono, and A. Kurnaedi, "Penerapan String Matching,” vol. 11, no. 2, pp. 262275.

[8] M. Noorfaik and S. Novianto, "Efisiensi Penggunaan Algoritma Boyer Moore untuk Prediksi Perilaku Orang melalui Interaksi di Twitter."

[9] A. A. Zabar and F. Novianto, "KEAMANAN HTTP DAN HTTPS BERBASIS WEB MENGGUNAKAN SISTEM OPERASI KALI LINUX Program Studi Teknik Komputer - FTIK Universitas Komputer Indonesia Jurnal Ilmiah Komputer dan Informatika ( KOMPUTA )," Ilm. Komput. dan Inform., vol. 4, no. ISSN : 2089-9033, pp. 69-74, 2015.

[10] R. Hidayatullah, "Pembuatan Desain Website Sebagai Penunjang Company Profile CV. Hensindo.," pp. 11-25, 2016. 